\title{
Help seeking by male victims of domestic violence and abuse: an example of an integrated mixed methods synthesis of systematic review evidence defining methodological terms
}

\author{
Alyson L. Huntley ${ }^{1 *}$ (D) Eszter Szilassy ${ }^{1}$, Lucy Potter ${ }^{1}$, Alice Malpass ${ }^{1}$, Emma Williamson $^{2}$ and Gene Feder ${ }^{1}$
}

\begin{abstract}
Background: Domestic violence and abuse is a violation of human rights which damages the health and wellbeing of victims, their families and their friends. There has been less research on the experiences and support needs of male victims than those of women. Historically research on men's experiences has not focused on what constitutes effective, needs-led service provision. The aim of this paper was to conduct an integrated mixed methods synthesis of systematic review evidence on the topic of help-seeking by male victims of domestic violence and abuse.

Methods: An integrated mixed methods synthesis approach was taken to enhance our understanding of the complex phenomenon of help seeking by, and service provision to male victims. This process also identifies gaps in the evidence. Using previously identified systematic review data; mixed methods data from four primary-level service evaluation studies, along with expert and patient consultation were used to develop research propositions. Primary-level qualitative interview and survey data from 12 studies of men experiences were mapped onto the propositions to support them.

Results: Fourteen propositions were composed. Seven propositions were supported or at least partly supported by the qualitative data. These supported propositions were used to make recommendations for policy and practice particularly concerning senvice preferences of male victims. The remaining seven propositions were not specifically supported by the qualitative data. These unsupported propositions were used to develop research recommendations concerning the need to further understand the potential blurred boundaries of victim-perpetrator, hybrid perpetrator-victim experiences, men who are/ have been victims of childhood sexual abuse and determining the level of risk for men. They also highlight the need to produce better guidance for the response of the police \& the criminal justice system. Finally, they highlight the need to produce the most appropriate senvice for men in terms of access, linkage, substance/alcohol abuse, mental health, sexuality, and race.
\end{abstract}

Conclusion: Integrated mixed-methods synthesis of systematic review evidence is a relatively novel approach. This approach can lead to recommendations for policy and practice as well as highlighting gaps in the research agenda as shown in this example.

Keywords: Mixed methods, Systematic review evidence, Domestic violence, Male victims, Help seeking

\footnotetext{
* Correspondence: alyson.huntley@bristol.ac.uk

${ }^{1}$ Centre for Academic Primary Care, Population Health Sciences, Bristol

Medical School, University of Bristol, Canynge Hall, 39 Whatley Road, Bristol BS8 2PS, England

Full list of author information is available at the end of the article
}

C C The Author(s). 2020 Open Access This article is licensed under a Creative Commons Attribution 4.0 International License, which permits use, sharing, adaptation, distribution and reproduction in any medium or format, as long as you give appropriate credit to the original author(s) and the source, provide a link to the Creative Commons licence, and indicate if changes were made. The images or other third party material in this article are included in the article's Creative Commons licence, unless indicated otherwise in a credit line to the material. If material is not included in the article's Creative Commons licence and your intended use is not permitted by statutory regulation or exceeds the permitted use, you will need to obtain permission directly from the copyright holder. To view a copy of this licence, visit http://creativecommons.org/licenses/by/4.0/ The Creative Commons Public Domain Dedication waiver (http://creativecommons.org/publicdomain/zero/1.0/) applies to the data made available in this article, unless otherwise stated in a credit line to the data. 


\section{Background}

Domestic violence and abuse (DVA) is a violation of human rights which damages the health and wellbeing of victims, their families and friends. There has been less research on the experiences and support needs of men experiencing DVA than those of women survivors [1]. Historically much of the research on men's experiences of DVA focused on prevalence and the forms of abuse suffered, and less on what constitutes effective, needs-led service provision [2]. More recent work has addressed these issues [3].

This integrated mixed methods synthesis (IMMS) builds on the systematic review evidence of four unpublished primary-level mixed methods service evaluation studies and a published synthesis of 12 primary-level qualitative interview and survey studies [4]. This IMMS enables us to further explore the barriers to help-seeking from formal support services in the broader context of men's experiences.

There is a risk that systematic reviews steer the direction of research away from questions for which we do not have enough data, or which have not been asked. In this sometimes contentious area of research on male victims' experiences of DVA, there are a number of important questions which need to be asked, but which can be obscured by what is already known. This paper seeks to broaden the scope of the conversation in this field by engaging both with what is known and what is not yet adequately known using a relatively novel mixed methods approach.

\section{Methods}

\section{Scope}

Help seeking by, and service provision to male victims of DVA. Definitions of relevant DVA terms can be found in Table 1.

\section{Data source}

We have previously conducted a systematic review of the relevant literature using standard methodology based on Cochrane principles [5]. This systematic review identified four mixed methods primary-level evaluations (quantitative and qualitative data) of the services for male victims of DVA and 12 primary-level qualitative studies of men's experiences of help seeking and service provision. The protocol of this systematic review was published on the Prospero website [6]. The four primary-level service evaluations were not published in a systematic review due to the small number of studies. The 12 primary-level qualitative studies were synthesised and published as a standalone systematic review and qualitative synthesis paper [4].

\section{Methodological approach}

Our IMMS was based on the mixed methods approach to systematic review evidence initially proposed by DixonWoods and colleagues and further developed by Heyvaert, Hanees and Obghena [7, 8]. Definitions of relevant IMMS methodological terms can be found in Table 2 .

In this synthesis we used a Narrative Summary approach facilitated by the development of propositions. Narrative Summary is often used in systematic reviews alongside systematic searching and appraisal techniques [7]. Narrative summary can vary from the simple description of findings through to more reflexive accounts that include commentary based on experience of the topic area. Narrative Summaries of the latter type can offering explanations that emphasise the sequential and contingent character of phenomena.

Despite methodological guidance, in practice Narrative Summary is still largely an informal approach and as such, is subject to criticism of its lack of transparency [7]. This is compounded by the fact that each Narrative Summary is different in nature based on the use of different combinations of evidence in a different format tackling a variety of evidence questions. As a consequence of this we also informed our methods from previously published IMMS of systematic review evidence [9-11].

Table 1 Definitions of terms used research concerning male victims of domestic violence and abuse

\begin{tabular}{|c|c|}
\hline Term & Definition \\
\hline $\begin{array}{l}\text { Domestic Violence and Abuse } \\
\text { (DVA) }\end{array}$ & $\begin{array}{l}\text { Any incident or pattern of incidents of controlling coercive or threatening behaviour, violence or abuse between } \\
\text { people aged } 16 \text { or over who are or have been intimate partners or family members, regardless of gender or } \\
\text { sexuality [1]. }\end{array}$ \\
\hline Referrers to DVA services & $\begin{array}{l}\text { Any professional person who can refer a victim of DVA to further formal support services even if it is an advocate } \\
\text { who will then refer the person onto services. This can be a health care, social care, charity or criminal justice } \\
\text { professional trained to perform this role. }\end{array}$ \\
\hline Signposting to services & $\begin{array}{l}\text { Victims may require different services outside what DVA services offer such as alcohol or drug services or specific } \\
\text { mental health support. Although it is possible that some of these services may be combined with DVA service } \\
\text { provision in some cases. }\end{array}$ \\
\hline $\begin{array}{l}\text { (Blurred boundaries of) Victim/ } \\
\text { perpetrator }\end{array}$ & Some perpetrators of DVA present to services as victims when that is not the case. \\
\hline $\begin{array}{l}\text { Hybrid perpetrator-victims } \\
\text { (experiences) }\end{array}$ & $\begin{array}{l}\text { Some victims may also be perpetrators and that this dual status might impact on the process of referral and the } \\
\text { interventions these patients might require. }\end{array}$ \\
\hline
\end{tabular}


Table 2 Definitions relating to Integrated mixed methods synthesis (IMMS) of systematic review evidence

\begin{tabular}{ll}
\hline Term & Definition \\
\hline Primary level studies/evaluations & $\begin{array}{l}\text { Studies/evaluations in which researchers collect data (can be quantitative, qualitative or both) } \\
\text { directly from their research participants. }\end{array}$ \\
Systematic review & $\begin{array}{l}\text { A systematic review attempts to identify, appraise and synthesize all the empirical evidence [from } \\
\text { primary level studies] that meets pre-specified eligibility criteria to answer a specific research } \\
\text { question. Researchers conducting systematic reviews use explicit, systematic methods that are se- } \\
\text { lected with a view aimed at minimizing bias, to produce more reliable findings to inform deci- } \\
\text { sion making [5]. }\end{array}$ \\
$\begin{array}{l}\text { Integrated mixed methods synthesis of } \\
\text { systematic review evidence (IMMS) }\end{array}$ & $\begin{array}{l}\text { Combining empirical evidence described in various kinds of primary level studies buy using } \\
\text { review to answer complex review questions and study complex topics and problems [8]. }\end{array}$ \\
Narrative Summary & $\begin{array}{l}\text { Narrative Summary is the selection, chronicling and ordering of evidence to produce an account } \\
\text { of the evidence, and can integrate quantitative and qualitative evidence through narrative }\end{array}$ \\
juxtaposition [7]. & $\begin{array}{l}\text { Propositions are ideas or statements derived from the initial data which have not necessarily } \\
\text { been subjected to empirical research but are amenable to testing through primary research. }\end{array}$ \\
Propositions & $\begin{array}{l}\text { Propositions which can be supported at least in part by relevant evidence facilitate the IMMS } \\
\text { approach and produce evidence that can be used for policy and practice. }\end{array}$ \\
Propositions unsupported by evidence & $\begin{array}{l}\text { Propositions that cannot be supported by relevant evidence do not facilitate an IMMS and } \\
\text { identify gaps in the evidence for research recommendations }\end{array}$ \\
\hline
\end{tabular}

In this IMMS, we composed propositions to explore service provision for male victims of DVA using the mixed methods primary-level evaluation study evidence identified in the systematic review and then looked to support these propositions with the evidence from the 12 primary-level qualitative interview and survey studies of men's experiences.

\section{Methodology in practice}

In practice, the above methodology was applied in individual and group work. (Fig. 1).

\section{Step1) stakeholder consensus}

The systematic review evidence was presented as part of a DVA stakeholder group (REPROVIDE Programme) consensus process for discussion. For the stakeholder group we identified experts in the field through existing contacts within the research team and through contacts of the REPROVIDE executive advisory group [12]. The group consisted of members from healthcare, safeguarding, police partnerships, academia, and third-sector organisations. Participants included three front line worker representatives of various independent charities specifically supporting male survivors, three front line health care professionals and two social care professionals working with survivors of DVA including male survivors.

The purpose of the consensus process was to explore and debate some controversial and difficult areas of practice. The meeting, which took place in September 2016, generated a constructive multi-professional debate around issues identified during the review process. The main outcome of the consensus process was to feed into the development of the General Practice-based training and advocacy support intervention for DVA as part of the REPROVIDE Programme [12]. However this process was also an invaluable information gathering and discussion activity for the present authors of this IMMS; assisting them in the formation of propositions in step 2.

\section{Step 2) proposition development}

The first author $(\mathrm{AH})$ drafted some example propositions from the primary-level service evaluation study data and the process was discussed face to face with the rest of the authors using a previous published exemplar of IMMS to clarify the process [11]. Each author then used the data from the primary-level service evaluation studies to draft propositions individually in a Word document. Several of the authors have significant expertise in DVA research (GF, EW, ES). These propositions were collated by $\mathrm{AH}$ and discussed as a group to reduce redundancy. From this process one set of propositions was drafted by $\mathrm{AH}$ and recirculated. After individual consideration, the group met again to further refine the propositions.

\section{Step 3) mapping the qualitative supporting evidence onto propositions}

The primary-level qualitative interview and survey data and published synthesis was discussed by the authors as a group [4]. The qualitative themes and associated data were then initially mapped onto the propositions by $\mathrm{AH}$. The propositions with supporting qualitative evidence in place were then discussed and edited as a group (face to face and by email) until all authors agreed with the IMMS achieved. Propositions not supported by qualitative evidence were also confirmed by the group. 


\section{Aim of synthesis}

To use an IMMS of the literature on service provision to, and help seeking by male victims of DVA to provide insight to the provision of services and any gaps in the evidence

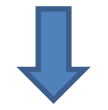

\section{Source of data}

A previously conducted systematic review entitled 'A mixed method systematic review of interventions in all settings for male victims of Domestic Violence and Abuse' containing mixed methods evidence of service evaluations and qualitative evidence of men experiences.

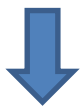

\section{Methodology}

Step 1: Stakeholder consensus - Broad discussion and information sharing around topic area as part of the REPROVIDE program grant process. Wide range of stakeholders including the authors of this paper.

Step 2: Proposition development - by authors, based on mixed methods service evaluation evidence and informed by stage 1 .

Step 3: Mapping the qualitative supporting evidence onto propositions- by authors, using the qualitative thematic evidence of men's experiences.

Step 4: Verification by REPROVIDE Patient and Public Involvement (PPI) group- two authors present and discuss propositions with the PPI group to ensure relevance of synthesis.

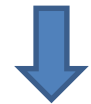

Recommendations

Verified by a PPI group of male victims of DVA
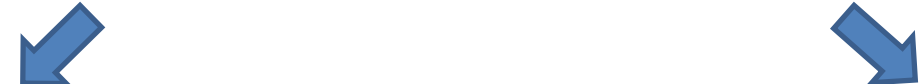

Policy \& practice

Research

Fig. 1 An integrated mixed methods synthesis (IMMS) of systematic review evidence for hep seeking for male victims of DVA

Step 4) verification by REPROVIDE patient and public involvement group

These propositions were presented by the research team (GF, ES) to four members of the REPROVIDE male victim Patient and Public Involvement (PPI) group during a meeting in February 2017 to discuss their relevance and check that they reflected reality.

Formulation of recommendations for, policy \& practice and future research

Propositions with supporting qualitative evidence were used by the research team to formulate recommendations for policy and practice. Propositions without supporting qualitative evidence were used to discuss the gaps in the evidence for help seeking for male victims of DVA.

\section{Results}

Systematic review evidence

The previous systematic review' A mixed method systematic review of interventions in all settings for male victims of Domestic Violence and Abuse' identified four primarylevel mixed methods evaluation studies [3, 13-15]. These primary-level evaluation studies described three interventions/service types. (Table 3) The systematic review also identified twelve relevant primary-level qualitative interview and survey studies of the experiences of male victims of DVA [16-27] (Table 4). 
Table 3 Details of primary-level service evaluation studies

\begin{tabular}{|c|c|c|c|}
\hline $\begin{array}{l}\text { Study ID } \\
\text { History of } \\
\text { service } \\
\text { Timeline }\end{array}$ & Details of services & $\begin{array}{l}\text { Population during } \\
\text { valuation }\end{array}$ & Objectives \\
\hline $\begin{array}{l}\text { Robertson } \\
\mathbf{2 0 0 6} \text { Dyn } \\
\text { Final } \\
\text { Evaluation } \\
\text { Report. } \\
\text { UK }\end{array}$ & $\begin{array}{l}\text { Five guiding principles } \\
\text { 1)That it is essential to } \\
\text { develop essential services } \\
\text { for GBT and heterosexual } \\
\text { men which are effective in } \\
\text { reducing risk and increasing } \\
\text { safety } \\
\text { 2) services must have a } \\
\text { clear definition of domestic } \\
\text { abuse } \\
\text { 3)a clear screening protocol } \\
\text { is essential in order to } \\
\text { identify and respond } \\
\text { appropriately to counter } \\
\text { allegations } \\
\text { 4) any service must have } \\
\text { the capacity to risk assess } \\
\text { referrals in order to identify } \\
\text { those who are most at risk } \\
\text { of experiencing abuse in } \\
\text { the future } \\
\text { 5) work with men who } \\
\text { have experienced domestic }\end{array}$ & $\begin{array}{l}\text { Total of } 171 \text { men } \\
\text { 'The typical Dyn client is a } \\
\text { white British male who is } \\
\text { less than } 40 \text { years old, and } \\
\text { reflecting the project's } \\
\text { status as a criminal justice } \\
\text { agency has been referred } \\
\text { to the project by the } \\
\text { police. } \\
\text { Where employment status } \\
\text { is known, equal } \\
\text { proportions are in full-time } \\
\text { work as are unemployed.' }\end{array}$ & $\begin{array}{l}\text { 1) To document the types } \\
\text { of services provided by the } \\
\text { DYN project including an } \\
\text { overview of the workload in } \\
\text { the } 12 \text { mth period. } \\
\text { 2) to understand the } \\
\text { process of screening } \\
\text { referrals to determine types } \\
\text { 3) to identity the different } \\
\text { levels of risk, fear, safety } \\
\text { and relationships issues } \\
\text { amongst the different types } \\
\text { of men } \\
\text { 4) To assess the impact of } \\
\text { DYN on QoL \& safety of } \\
\text { men } \\
\text { 5) to determine feedback } \\
\text { men have about the DYN } \\
\text { project } \\
\text { 6) To identify links in } \\
\text { working practice between } \\
\text { DYN and WSU- benefits \& } \\
\text { challenges }\end{array}$ \\
\hline
\end{tabular}

Debbonaire 2008 [14] A report of an evaluation of the Men's Advice Line UK
There is a helpline worker, supervised by the Respect Phone line Co-ordinator. The helpline is open six hours per day on three weekdays per week. Callers can contact the service by email. The helpline has Type Talk and Language Line capability enabling it to respond a wider diversity of callers.
All interviewees were male. Interviewees came from 15 different counties in England and Wales. 15 (68.2\%) of the interviewees identified as "white", "white British" or "white English".

$3(13.6 \%)$ identified as AfroCaribbean or Black, 2 (9.1\%) identified as "Asian" and a further 2(9.1\%) as "mixed race".

Age of caller (yrs)

$21-294.5 \%$

30-39 54.5\%

40-49 18.2\%
Methods

Recommendations arising

- Case files

- Case

studies

- Client

Interviews

- Key

Informant

Interviews

- Participant observation

(n)

$$
\text { in }
$$

Conducting an empirical investigation into whether the FSU9 risk assessment form should be adapted specifically for male victims, 3) Conducting an empirical investigation into the respective risk profile of heterosexual men and their partners to inform service providers as to the nature of counterallegations

4) Considering the development of a dedicated domestic abuse strategy for GBT men as their levels of risk and support uptake warrant different models of service provision.

5) Considering the development of a dedicated domestic abuse strategy for heterosexual men

as their levels of risk and support uptake warrant different models of service provision.

6) Developing a set of agreed standards for work with men who have experienced domestic abuse to ensure that interventions identify and reduce risk while holding perpetrators to account.

That the Men's Advice Line considers extending the opening hours for one night per week to $8 \mathrm{pm}$ for a trial period to see if this helps callers who can't ring during office hours. 
Table 3 Details of primary-level service evaluation studies (Continued)

\begin{tabular}{|c|c|c|c|c|c|}
\hline $\begin{array}{l}\text { Study ID } \\
\text { History of } \\
\text { service } \\
\text { Timeline }\end{array}$ & Details of services & $\begin{array}{l}\text { Population during } \\
\text { valuation }\end{array}$ & Objectives & Methods & Recommendations arising \\
\hline
\end{tabular}

50-59 22.7\%

Debbonaire 2010 [15] Mens advice line client satisfaction report 20092010 Scotland. consent.

Victim 16
Four staff and one coordinator now take calls. The opening hours of both lines are now $10 \mathrm{am}-5 \mathrm{pm}$ with the lines closed between 1 and 2. Emails are also used as a method of providing advice, information and support on both lines.
The callers were from around England, Wales \&

A total of 67 callers gave

Perpetrator 2

Perpetrator presenting as victim 9

Professional 4

Friend/family 4

Missing data 1

TOTAL (n) 36

Ages

Under 1800

18-2100

$21-3013$

$31-4063$

41-50 141

51-60 71

Over 6001

Missing 90

TOTAL 369

Ethnicity

WhiteBritish 186

BI'k/A-Carib 11

Indian/

Pakistani/

Asian 22

African 10

Other 30

Missing 110

Totals 369

Sexuality

Heterosex 279

Lesbian/gay/bisexual 10

Missing 80

Hester 2012

[3]

Exploring the

service and

support needs

of male,

lesbian, gay,

bi-sexual and

transgendered

and

black and

other minority

ethnic victims

of domestic

and sexual

violence
Of 111 service providers in the areas of London, the North West and South West of England who were possibly offering services to male, LGBT and/or BME victims of domestic or sexual violence, 76 responded. These represented a wide range voluntary, health and criminal justice sectors, as well as private solicitors and counsellors responded. This included 58 services from the voluntary, 15 from the statutory and three from the private sector. of services across the
The study included Male (heterosexual) victims of domestic and sexual violence

Lesbian, gay, bi-sexual and transgender victims of domestic and sexual Violence

Male black and minority ethnic victims of domestic and sexual violence and female BME victims of sexual violence

\section{samples}

Hetero/gay/bi/TG

Online $6,2,1,1$

nterviews 5,2,0,0

Service data 22,0,0,0

Focus grp 0,0,015

BME 13,1,0,4

White $16,7,0,12$

Other 4,0,0,0

detailing the findings of the above analysis and making recommendations if necessary about future development.

The survey focussed purely - Phone on satisfaction with the call. interviews 1. To investigate the • Email data satisfaction of people gathering contacting the Men's

Advice Line with the service they receive, by email or phone

2. To find out in particular if the callers/e-mailers were responded to promptly and courteously, whether or not they received help and advice they wanted, their overall levels of satisfaction, the type of advice and support they received and any suggestions for improving the service 3. To investigate this with a cross-selection of callers/ mailers if possible

4. To prepare two short reports on the findings from each customer satisfaction survey, with, if appropriate, any recommendations for improving the service

The project aimed to begin Victims of to plug the existing knowledge gap via research with service providers and service users in three areas of England with the research focused on the

extent and nature of both domestic and sexual violence, and the related service use and service needs, for under-researched population groups:
DVA

- Face to

face

Interviews

- Focus

groups

- On-line

survey

Service

providers

- Face to

face

Interviews
Nothing explicit
The 'Gold Book' directory of domestic violence services should list services able to support heterosexual and/ or BME male and LGBT victims of domestic violence.

Service providers generally need training to understand and address domestic and sexual violence as these affect heterosexual and/or BME male and LGBT victims. There needs to be consideration of how support for heterosexual and/or BME male and LGBT victims might be located within existing services or through specialist provision. Third sector and specialist 
Table 3 Details of primary-level service evaluation studies (Continued)

\begin{tabular}{|c|c|c|c|c|c|}
\hline $\begin{array}{l}\text { Study ID } \\
\text { History of } \\
\text { service } \\
\text { Timeline }\end{array}$ & Details of services & $\begin{array}{l}\text { Population during } \\
\text { valuation }\end{array}$ & Objectives & Methods & Recommendations arising \\
\hline & & & & & $\begin{array}{l}\text { domestic and sexual } \\
\text { violence services may be } \\
\text { best placed to lead on this. } \\
\text { Different forms of provision } \\
\text { should also be considered, } \\
\text { including helplines } \\
\text { with long opening hours, } \\
\text { and more outreach } \\
\text { (mentioned by heterosexual } \\
\text { men); web-based } \\
\text { information } \\
\text { There needs to be wider } \\
\text { dissemination of risk } \\
\text { assessment protocols for } \\
\text { male victims of domestic } \\
\text { violence in order to identify } \\
\text { those who may also need } \\
\text { support services for the } \\
\text { perpetration of violence } \\
\text { and abuse }\end{array}$ \\
\hline
\end{tabular}

\section{Service evaluation studies}

Three papers describe two standalone male victim support services [13-15]. The fourth paper was a broader evaluation of service providers in selected areas of England [3].

1.The Dyn project located within the Women's safety unit Cardiff, UK began accepting referrals in January 2005, although relocated to a different site subsequently [13]. The evaluation was for a 12-month period and included data from 171 men. Quantitative and qualitative data was collected via case files, case studies, client interviews, key informant interviews and participant observation. This evaluation made six main recommendations for practice.

$2 \& 3$. There are two separate evaluation reports of a men's advice line based in London $[14,15]$. The first was conducted in February 2007 following a relaunch of an advice line for male victims of DVA by the organisation RESPECT [14]. Interviewees were recruited from mid-January-mid April 2008. All 21 interviewees were male and came from 15 different counties in England and Wales. Quantitative and qualitative data collection was via phone interviews and email. These data were narratively presented, and the key recommendation was that the service considered extending the opening hours for one night per week to $8 \mathrm{pm}$ for a trial period to see if this helped callers who could not ring during office hours.

The second report was in 2010 and was a satisfaction report conducted November to December 2009 and late January- early February 2010 [15]. Since the first evaluation the helplines had expanded in staff numbers and opening hours. A total of 67 callers gave consent and were from England, Wales \& Scotland. Quantitative and qualitative data were collected by via phone interviews and email. There were no specific recommendations from this report.

4. The fourth publication described a pan service research evaluation in the areas of London, the North West and South West of England exploring the service and support needs of male, lesbian, gay, bi-sexual, transgendered, black and other minority ethnic victims of domestic and sexual violence [3]. The evaluation included male (heterosexual) victims of domestic and sexual violence. Quantitative and qualitative data collection was via face to face interviews, focus groups and on-line surveys with victims of DVA as well as face to face interviews with service providers. This evaluation made six main recommendations for practice.

\section{Qualitative interview and survey studies}

The searches identified 12 relevant primary-level qualitative studies of the experiences of male victims of DVA. Six studies were conducted in the UK, four in the USA and one each in Sweden and Portugal and all were published between 2006 and 2017.

The synthesis of the qualitative interview and survey data is published [4]. In this synthesis, we generated key themes in two main categories (1) barriers to helpseeking and (2) experiences of interventions and support. We derived five themes on the barriers to initial disclosure and help-seeking by male victims of DVA. Three themes were closely related: fear of disclosure, 
Table 4 Details of primary-level qualitative interview and survey studies. First published in Huntley et al 2019. https://bmjopen.bmj. com/content/9/6/e021960.long

\begin{tabular}{|c|c|c|c|c|c|}
\hline $\begin{array}{l}\text { Author } \\
\text { Date } \\
\text { Country } \\
\text { Setting/recruitment } \\
\text { source }\end{array}$ & Study design & $\begin{array}{l}\text { Research question/ aim } \\
\text { of study }\end{array}$ & $\begin{array}{l}\text { Participants } \\
\text { demographics } \\
\text { Age } \\
\text { Ethnicity } \\
\text { Education } \\
\text { Marital status }\end{array}$ & $\begin{array}{l}\text { Theoretical } \\
\text { approach }\end{array}$ & $\begin{array}{l}\text { Method of data } \\
\text { analysis }\end{array}$ \\
\hline
\end{tabular}

\section{Bacchus}

$2016[16]$

UK

Two generic sexual health clinics and one specialist sexual health clinic for (LGBT) patients in London.

\section{Donovan \\ 2006 [17] \\ UK}

Individuals were recruited from community groups and networks across the UK.

\section{[18] \\ PhD thesis}

USA

Participants identified via social service agencies and social organizations, as well as social media sites serving African American gay men

\section{Hines 2010}

[19]

Men recruited via

Domestic Abuse Helpline for Men and Women, a national IPV hotline specializing in men victims, Web sites, newsletters, blogs, and electronic mailing lists

\section{Hogan 2016 \\ [20] \\ PhD thesis}

\section{UK}

Men recruited by

domestic abuse services

UK-wide $(n=2)$ mental

health support services \& drug/alcohol support services UK-wide $(n=9)$.

Snowballing technique $(n=2)$ Presentation of preliminary findings at 2 UK conferences $(n=2)$ online support forums for male victims of domestic
Mixed method

study survey \&

individual semi-

structured

interviews

To illustrate the use of a

case series mixed

methods for integrating

interviews and survey

data on gay and bisexua

men's experiences of

negative \& abusive

behaviour in the context of intimate relationships.

Mixed method To provide a detailed study using UK picture of same sex wide survey, focus domestic abuse, while at group and individual interviews the same time being able to compare same sex and heterosexual experiences of such abuse

Qualitative interview study

$N=19$ for interviews

Mean age 39 years (range 21-57\%)

Ethnicity:

Asian/asianbritish 5.3\%

White $89.5 \%$

Other 5.3\%

paid employment 100\%

Five focus groups with lesbians, gay men and

heterosexual women and men $(n=21)$.

Semi-structured

interviews with 67

individuals identifying as

lesbian (19), gay male

(19), heterosexual (14

women, 9 men), bisexual

(3) or queer (3),

13 male volunteers 18-

40 yrs. identified as

African American, Black,

of African descent and/or

biracial; identified their

sexual orientation as gay

or same-gender-loving;

and had experienced at

and he

behaviours related

intimate partner violence.

ast one form of intimate abuse within a past and/or current relationship.

Online

questionnaire or telephone

interview (same

questions)

(n)

An in-depth, descriptive

299 men

examination of men who Mean age $=40.49 \mathrm{yrs}$.

sustained severe IPV from White $86.8 \%$

their women partners

within the previous year

and sought help.

All in heterosexual

relationships

$56.5 \%$ currently in a

relationship with their

woman partners, $47.5 \%$

marriage followed by

separation (17.9\%).

Relationships lasted on

average 8.2 yrs.,

Qualitative $\quad$ To explore: (a) men's

interview study experiences of femaleperpetrated IPV, including their experiences of physical \& psychological/ emotional abuse; (b) men's help-seeking experiences and/or their perceptions of utilising support services/support networks; and (c) barriers to men leaving their abusive relationship.

$n=23$ Men $>18$ yrs. who self-identified as a victim of female-perpetrated IPV.

Race/ethnicity: White British (16) White other (5) British Pakistani (1)

Black Afro Caribbean (1)

Age: (range) 24-74

(mean: 47)

Length of abusive relationship (range): 6
Pragmatism ("what The initial coding works as the truth framework followed a regarding the deductive approach research questions followed by open under coding in an inductive investigation") process which allowed new themes to emerge

None stated

No details approach was also weeks - 31 years (mean: 12 years 5 months) Number of abusive
Constructivist grounded theory approach In addition, constructivist epistemological perspective as a part of the grounded theory used

None stated

Qualitative responses were coded independently by 2 research assistants \& any discrepancies were resolved by the first author.

Contextualist

Constant comparative analysis involves four phases of coding: initial coding, focused coding, axial coding, and theoretical coding.

perspective (straddles essentialism \& constructionism)
Thematic analysis was following the six-phase process set out by Braun and Clarke (2006). used to analyse the data 
Table 4 Details of primary-level qualitative interview and survey studies. First published in Huntley et al 2019. https://bmjopen.bmj. com/content/9/6/e021960.long (Continued)

\begin{tabular}{|c|c|c|c|c|c|}
\hline $\begin{array}{l}\text { Author } \\
\text { Date } \\
\text { Country } \\
\text { Setting/recruitment } \\
\text { source }\end{array}$ & Study design & $\begin{array}{l}\text { Research question/ aim } \\
\text { of study }\end{array}$ & $\begin{array}{l}\text { Participants } \\
\text { demographics } \\
\text { Age } \\
\text { Ethnicity } \\
\text { Education } \\
\text { Marital status }\end{array}$ & $\begin{array}{l}\text { Theoretical } \\
\text { approach }\end{array}$ & $\begin{array}{l}\text { Method of data } \\
\text { analysis }\end{array}$ \\
\hline
\end{tabular}

abuse \& male victim sup-

port blogs $(n=8)$

\section{Machado \\ 2017}

\section{Portugal}

Male victims of IPV in who had sought formal

help from DV agencies heterosexual relationships
Participant's demographics structured interview followed by semi-

iew

\section{McCarrick \\ 2016 [22]}

UK

Charitable agency that support male victims \& via advertisements placed on a website.

\section{Morgan \\ 2014 [23]}

UK

Men recruited from GP surgeries in south west of England

\section{Morgan \\ 2016 [24]}

UK

Participants recruited from websites of UKbased organisations supporting male victims of IPV.

Sweden

Primary health care

\section{Simmons \\ 2016 [25]}

\begin{abstract}
Unstructured
Face-to-face and

Skype qualitative

interviews.

To explore men's experience of the UK Criminal Justice System (CJS) following femaleperpetrated IPV
\end{abstract}

Cross-sectional survey \& followup interviews investigating the

impact of men's relationships on their health

Semi-structured interview methodology

To expand the current body of knowledge on male help-seeking in relation to DVA by measuring \& characterising helpseeking practices.

To investigate male victims' experiences of female-perpetrated IPV

Qualitative interview study
To develop a theoretical model concerning male victims' processes of disclosing experiences of victimisation to health care professionals in sweden. relationships: One (17), Two (6)

$N=10$

mean age 51.6 yrs. (range

None stated

35-75 yrs)

$50 \%$ had $<12$ yrs.

education

$n=6$ employed

$n=4$ retired

$n=3$ lower class

$n=3$ lower middle class

$n=2$ middle class

$n=2$ upper middle class

6 male participants (45-

$60 \mathrm{yrs})$ over $18 \mathrm{yrs}$. and

having experienced

female-perpetrated intim-

ate partner violence (IPV) and subsequent involvement with the CJS

No demographic details

Grounded theory

$n=7$

Researchers asked

participants not to disclose their

demographics of age, occupation etc. range of length of relationship 3-

13 yrs. range of time since relationship finished 18mths-14 yrs

Informants were

recruited from

respondents in a

quantitative study of

being subjected to IPV, III

health, seeking behaviour conducted in men and women in the general population ( $n=1510$, response rate $37 \%$ ) and at two primary health care centres $(n=129$, response rate $70 \%)$ recruited from the random population sample.

Survey consists of To examine the needs of five closed ended questions two open-ended male victims to identify

2010 [26]

USA

960 DVA services across USA factors that block men from seeking help.'
Sixty-eight agency

representatives

responded.

Mean age 43 yrs. 72\%

female

81\% Caucasian questions

\& 13 demographic approach

Interpretative phenomenological analysis

in

A coding framework was used that was developed in conjunction with colleagues across the wider study.

interpretative phenomenological (theory) analysis (IPA)

The scripts were transcribed verbatim from audio recordings using the Jefferson technique \& analysed using IPA.
After each interview,

Constructivist grounded theory

codes \& categories

created in analysis helped to choose the next informant, and the guide was modified to explore related topics \& elaborate categories. A constant comparative analysis both within an interview and between interviews. Next focused coding was used in which most significant line-by-line codes were used

None stated

Qualitative data were coded to thematic units. Similar units with meaning related to male victims were assigned to categories and organized 
Table 4 Details of primary-level qualitative interview and survey studies. First published in Huntley et al 2019. https://bmjopen.bmj. com/content/9/6/e021960.long (Continued)

\begin{tabular}{|c|c|c|c|c|c|}
\hline $\begin{array}{l}\text { Author } \\
\text { Date } \\
\text { Country } \\
\text { Setting/recruitment } \\
\text { source }\end{array}$ & Study design & $\begin{array}{l}\text { Research question/ aim } \\
\text { of study }\end{array}$ & $\begin{array}{l}\text { Participants } \\
\text { demographics } \\
\text { Age } \\
\text { Ethnicity } \\
\text { Education } \\
\text { Marital status }\end{array}$ & $\begin{array}{l}\text { Theoretical } \\
\text { approach }\end{array}$ & $\begin{array}{l}\text { Method of data } \\
\text { analysis }\end{array}$ \\
\hline & questions & & $\begin{array}{l}\text { 7.3\% Hispanic } \\
\text { 5.9\% African American } \\
\text { 88.2\% held an academic } \\
\text { degree } \\
\text { 84\% were professional or } \\
\text { managerial staff in the } \\
\text { DVA organizations }\end{array}$ & & $\begin{array}{l}\text { into themes and further } \\
\text { reviewed by research } \\
\text { team to enhance face \& } \\
\text { content validity. }\end{array}$ \\
\hline $\begin{array}{l}\text { Valentine } \\
\mathbf{2 0 1 3}[27] \\
\text { USA } \\
\text { Men recruited } \\
\text { from university-affiliated, } \\
\text { outpatient HIV/AIDS pri- } \\
\text { mary care clinic }\end{array}$ & $\begin{array}{l}\text { Qualitative } \\
\text { interview study }\end{array}$ & $\begin{array}{l}\text { To qualitatively explore } \\
\text { the ways in which such } \\
\text { men find meaning } \\
\text { following their } \\
\text { experiences of partner } \\
\text { abuse }\end{array}$ & $\begin{array}{l}\text { ( } n=28) \geq 18 \text { yrs., English- } \\
\text { speaking, currently re- } \\
\text { ceiving HIV-related care } \\
\text { at the clinic site. } \\
\text { Mean age } 43.6, \text { SD } 56.2 \\
\text { Male 24, Transgender } 4 . \\
\text { Gay 23, Bisexual } 3 \\
\text { Bi spirit 1, Other } 1 \\
\text { Currently in relationship } \\
12 \\
\text { Living with partner } 6 \\
\text { Relationship status } \\
\text { unknown } 10 \\
\text { White/European } 13 \\
\text { Black/African American } 8 \text {, } \\
\text { Latino/Hispanic } 2 \\
\text { American, Indian/Alaskan } \\
\text { Native } 3 \text { Biracial/ } \\
\text { multiracial }\end{array}$ & None stated & $\begin{array}{l}\text { Data analysis was } \\
\text { conducted by a team } \\
\text { who contributed to the } \\
\text { reading, coding, } \\
\text { categorizing, Consistent } \\
\text { with conventional } \\
\text { content analysis, no } \\
\text { codes, categories, or } \\
\text { themes were specified a } \\
\text { priori (Hsieh \& Shannon, } \\
\text { 2005). To establish } \\
\text { dependability (Morrow, } \\
\text { 2005), all three reviewers } \\
\text { met to compare codes } \\
\text { and reach a consensus. }\end{array}$ \\
\hline
\end{tabular}

challenge to masculinity and commitment to relationship. Other themes were diminished confidence/despondency and the invisibility/perception of services.

Four themes emerged relating to experiences of interventions and support: initial contact, confidentiality, appropriate professional approaches and inappropriate professional approaches. The theme of confidentiality is closely linked to the themes of appropriateness of professional approaches. (Additional file 1).

Propositions and supporting evidence The development process described in the methods produced 14 propositions. (Table 5) Seven propositions were fully or at least partly supported by the qualitative data and an IMMS was achieved. The remaining seven propositions were not supported specifically by the qualitative data and could not undergo an IMMS.

\section{Propositions 1-7}

These propositions were fully or at least partly supported by the qualitative evidence and an IMMS was achieved leading to policy and practice recommendations.

Proposition 1: It is important to understand who are acceptable referrers to a male victim service.

\section{Relevant qualitative themes}

This proposition most closely relates to the qualitative themes of Initial contact, Appropriate professional approach and Inappropriate professional approach and is specifically supported by qualitative data from seven primary qualitative studies covering community based DVA services as well as primary health care and sexual health services [16-18, 20, 22, 23, 25].

\section{Supporting evidence}

The qualitative findings suggest a mixed response by men to referral from primary health care, with some men not perceiving it as a source of help as well as doubting the compassion and approach to confidentiality of general practitioners $[16,25]$. Other men felt that general practice is a good place to disclose DVA and be referred, and that this process is facilitated by continuity of care and an individual approach by clinicans $[16,23,25]$.

The data around the response of police were also mixed, but generally the criminal justice system is not perceived as receptive to disclosure of DVA and referral with the fear of being wrongly accused of perpetration and inappropriate reaction in some cases [17, 18, 20, 22]. There are no qualitative data on the acceptability of referrals from other professional support services in the community, such as drug and alcohol workers. 
Table 5 Contribution of the papers to the responses to the propositions

Propositions
1. It is important to understand who are acceptable referrers to a male victim service
2. If men's services are linked to women's services, we need to know which features of the 'shop
front' are important so as not to put men off seeking help

front' are important so as not to put men off seeking help

3. There is a need to publicise our services for male victims to appeal to men of all backgrounds.

4. It is important that we understand what male victims mean by "practical help" or "advice about what to do"

5. A sensible approach to initially provide practical advice to male victims which then may help them to talk about their emotional issues.

6. Understanding what male victims tell us about the ways in which they like to seek help is important. E.g. online, by phone, continuity of contact

7. There is a need to know what the core training needs of service providers, and ongoing support needs of male survivors are.

\section{Papers}

Bacchus 2016 [16]

Donovan 2006 [17]

Frierson 2014 [18]

Hogan 2016 [20]

Morgan 2014 [23]

Simmons 2017

McCarrick 2016 [22]

Donovan 2006 [17]

Frierson 2014 [18]

McCarrick 2016 [22]

Tsui 2010 [26]

Donovan 2006 [17]

Frierson 2014 [18]

Hines 2010 [19]

Hines 2010 [19]

Simmons 2017

Machado 2017

Morgan 2014 [23]

Bacchus 2016 [16]

Frierson 2014 [18]

Morgan 2014 [23]

Tsui 2010 [26]

Simmons 2017

Bacchus 2016 [16]

Frierson 2014 [18]

Hogan 2016 [20]

Morgan 2014 [23]

Simmons 2017

Bacchus 2016 [16]

Donovan 2006 [17]

Frierson 2014 [18]

Hogan 2016 [20]

McCarrick 2016 [22]

Morgan 2014 [23]

Morgan 2016 [24]

Simmons 2017

Tsui 2010 [26]

No significant contribution from papers

None

None

None

None

No significant contribution from papers

No significant contribution from papers

\section{Most relevant themes}

Initial contact

Appropriate professional

approach

Inappropriate professional approach

invisibility/perception of services

invisibility/perception of services

Fear of disclosure

Commitment to

relationships

Appropriate professional approaches

Diminished confidence and despondency

\section{Confidentiality}

Appropriate professional approaches

Confidentiality Appropriate professional approaches Inappropriate professional approaches

No relevant themes

No relevant themes

No relevant themes

No relevant themes

No relevant themes

No relevant themes

No relevant themes

14. There is a need to understand how linkage/co-ordination between services supporting male victims can be maximised.

There was only one study which recruited men from sexual health clinics and these men appeared to have no problems with non-medically trained advisors supporting and referring them on [16].

There is a consistent theme that female professional help in referral is acceptable, if not preferable for male victims of DVA with no comparable discussion around male professional help in these settings [16, 20, 23, 25].

\section{P1 summary}

There is no clear message about preference on disclosing to professionals in health care settings and being 
referred, and mixed feelings concerning the police. There is a lack of evidence on community support services. However, there is a consistent message that female professional help is acceptable.

Proposition 2: If men's services are linked to women's services, we need to know which features of the 'shop front' are important so as not to put men off seeking help.

\section{Relevant qualitative themes}

This proposition is most related to the qualitative themes of Invisibility/perception of services and is specifically supported by qualitative data from four of the primary-level qualitative studies $[16,18,22,26]$.

\section{Supporting evidence}

There was no significant discussion in the studies around the need for separate services for male victims, although it was specifically mentioned in the Tsui study [26]. What appeared to be more important to men was the lack of visibility and targeting of services towards men, and thus a perception, or perhaps the reality of a lack of access to such services $[16,22,26]$. This also links to the discussion by men that there is a lack of public awareness and political engagement of male victims of DVA [26].

\section{P2 summary}

There is no direct evidence about what a 'shop front' of services for male victims should look like; rather the evidence is that men are more concerned about access to services in the first instance.

Proposition 3: There is a need to publicise our services for male victims to appeal to men of all backgrounds.

\section{Relevant qualitative themes}

This proposition broadly relates to the qualitative theme of Invisibility/perception of services and is specifically supported by qualitative data from three of the primarylevel qualitative studies [17-19].

\section{Supporting evidence}

Donovan and Hester summed up the issue discussed in several studies as 'heterosexism of individual professionals' which can lead to a sense of isolation and a low expectation of services from the LGBT population [17]. There is some mention of ethnic barriers [19] to help seeking but the majority of the men in the studies were of White background with the exception of the Frierson study [18].

\section{P3 summary}

There is a lack of evidence of services being publicised to appeal to men of all backgrounds. Issues are raised about bias in favour of white, heterosexual males.

Proposition 4: It is important that we understand what male victims mean by "practical help" or "advice about what to do."

\section{Relevant qualitative themes}

This proposition relates in part to the qualitative themes of Fear of disclosure and Commitment to relationships and is specifically supported by four of the 12 primary qualitative studies [19, 21, 23, 25].

\section{Supporting evidence}

Some of the common fears of men disclosing DVA were losing the custody of their children, financial implications, and possibility of having 'nowhere to go'. This suggests that legal and housing advice would be welcome $[19,25]$. Another common expression of help was around the desire to help their partner. In other words, potentially getting their partners help for their behaviour [19]. The clinicians and DVA support services would not have to necessarily support both parties on their own but potentially facilitate access/ refer to appropriate support for the partner.

In Machado and colleagues' primary-level interview study male heterosexual victims of DVA report how informal help-seeking leads on to formal help-seeking but they also say 'However, the overwhelming majority of participants rated formal sources as unhelpful, especially the services of the judicial system'. [21] Conversely, men reported that they had received valuable support from friends, family and colleagues at work. However not all men's accounts of accessing informal help were not always positive [23].

\section{P4 summary}

The evidence gives a strong steer as to what is important to men: children, money, housing, and their partners situation featuring in their narratives. The evidence also suggests they may not seek formal support for these issues but rather look for help from family and friends.

Proposition 5: A sensible approach to initially provide practical advice to male victims which then may help them to talk about their emotional issues.

\section{Relevant qualitative themes}

This proposition most closely relates to the qualitative themes of Appropriate professional approaches and Diminished confidence and despondency and is specifically addressed by five of the original 12 primary-level qualitative studies $[16,18,23,25,26]$. 


\section{Supporting evidence}

This proposition would appear to be sensible as we know that often a crisis has to occur before men seek help. Therefore emergency legal, financial and medical help would be the most practical initial response [18, $25]$. The qualitative studies also report that men can minimise or downplay their experiences, so providing practical advice is likely to be less daunting than a specific therapeutic intervention $[16,18,26]$. The primarylevel qualitative studies also report that professional interaction and continuity of contact (as in general practice), gives time for men to feel they can trust the professional and be comfortable in discussing their situation in more detail $[16,23]$.

\section{P5 summary}

Whilst there is no direct evidence that providing practical advice first facilitates emotional support, some indirect evidence regarding men's interaction with services suggests this is a sensible strategy.

Proposition 6: Understanding what male victims tell us about the ways in which they like to seek help is important. E.g. online, by phone, continuity of contact

\section{Relevant qualitative themes}

This proposition most closely relates to the qualitative themes of Confidentiality and Appropriate professional approaches and is specifically supported by five of the twelve primary-level qualitative studies $[16,18,20,23$, 25].

\section{Supporting evidence}

No specific routes of help were discussed by the men in the included studies but there was a strong theme of the need for confidentiality and physical privacy in disclosing $[16,20,23,25]$. Men seemed to appreciate continuity of care from services, and to prefer disclosing to female professionals $[16,18,23]$.

\section{P6 summary}

There is no evidence in the primary-level qualitative studies as to the preference of ways e.g. phone, face to face men would like to communicate. However, the need for both confidentiality and physical privacy featured strongly.

Proposition 7: There is a need to know what the core training needs of service providers, and ongoing support needs of male survivors are.

\section{Relevant qualitative themes}

This proposition most closely related to the qualitative themes of Confidentiality, Appropriate professional approaches and Inappropriate professional approaches and is specifically supported by nine of the 12 primary-level qualitative studies [16-18, 20, 22-26].

\section{Supporting evidence}

These themes from the qualitative synthesis can inform guidance on the approach to service provision via 1)the importance of a private, confidential space to talk in; 2) the importance of being believed and listened to; 3 ) that the professional is knowledgeable about DVA (for example, because someone has left their partner does not mean they are not at risk); 4) not to avoid difficult conversations; to take disclosure seriously and not to use humour; 5) professionals should acknowledge sexuality and ethnicity; 6) to avoid assumptions about sexuality (particularly heteronormative assumptions) and 7) appropriate transparent signposting. The qualitative themes demonstrate the importance of a facilitative environment, sensible timing and effective communication skills in trust building and effective immediate response [4].

\section{P7 summary}

The evidence gives a strong steer as to what men expect out of a professional service both in terms of practical requirements e.g. confidential space and emotional support.

Propositions 8-14 These propositions were not supported by the primary-level qualitative study evidence and an IMMS was not achieved, identifying gaps in the evidence. Some of the proposition topics were briefly mentioned in the qualitative papers but with no evidence available to use for an IMMS.

Proposition 8: It is important that we use the most appropriate approach to the potential blurred boundaries of victim -perpetrator (to provide support and not to make the man feel like it is surveillance)

McCarrick and colleagues interviewed men who were frustrated and distressed by the confusion over victim/ perpetrator role by the criminal justice system but no practical recommendations on this issue were discussed [22].

Proposition 9: There is a need to understand the appropriate approach to hybrid perpetrator-victim experiences.

Proposition 10: There is a need to understand the appropriate approach to discussing the current experiences of men who are/have been victims of childhood sexual abuse.

Proposition 11: There is a need to understand the most appropriate and adequate way of determining the level of risk a man is at (bearing in mind current risk tools are underdeveloped). 
Proposition 12: There is a need to know if it is possible to have a single service (point of access) to provide appropriate support and linkage to other services to male victims from all backgrounds.

Proposition 13: For men with experience of substance/alcohol abuse or mental health problems we need to know how it is best to signpost to relevant services.

McCarrick mentions that mental health issues and lack of confidence e.g. post-traumatic stress disorder may prevent men accessing services [22].

Proposition 14: There is a need to understand how linkage/co-ordination between services supporting male victims can be maximised.

There were no significant primary-level qualitative data to provide any specific support to this proposition although it was acknowledged as an important issue in a couple of the studies [26, 27]. Two further studies included men who talked about the importance of peer support and wanting to give something back [20, 22]. This could be a mechanism for linking men together and sharing knowledge of services. It was pointed out by one man that it was important that the service signposted to was useful or there was no point in referring on $[20]$.

\section{Recommendations for policy \& practice and future research}

Whilst the evidence and evidence gaps we have articulated are likely to be universally relevant to male victims of DVA across the world, country-specific policy, practice and service provision does differ. As all four of the primary-level evaluation studies were based in the UK, our policy and practice recommendations are also UK orientated. That said, the fundamentals of our recommendations are likely to be broadly applicable to many countries. Recommendations were derived from the propositions by the one author (AH) and discussed and modified by the other authors until consensus was reached. (Fig. 2).

\section{Discussion}

This is the first IMMS of systematic review evidence on help seeking by and service provision to male victims of DVA. We have generated recommendations from our synthesis based on what men would ideally want from a service and high-light significant gaps in the evidence for service provision. Our work adds to the development of IMMS within health and social care research by promoting the use of this relatively novel methodology, defining terms and extending the methodology by using extensive stakeholder involvement.

In this discussion, we firstly debate the service provision in light of the evidence of the needs and actual experience of service provision by male victims of DVA and secondly contextualise the gaps in the evidence identified and make recommendations on the future of research in these areas. We acknowledge that these two tasks are not mutually exclusive.

\section{Policy and practice recommendations based men's needs and actual experience}

Propositions 1-7 have informed policy and practice recommendations regarding initial contact and approach, referral and ongoing care of male victims of DVA by professionals. They also identify the wider issues of awareness of male victims of DVA both by professional services and the public alike. This indicates a role for primary prevention efforts and wider media awareness campaigns around men's health.

Society is becoming more aware of male victims of DVA, and research, practice and policy are progressing, However, there are still many obstacles, not in the least unrelenting financial pressure on the DVA service sector and now in 2020 we have the impact of the Covid-19 crisis [28].

We need to promote an intersectional approach in existing front-line organisations as well as supporting the development of new male victim needs-led support schemes. Robust evidence of effectiveness of interventions and appropriate resources supporting the running of these organisations/schemes are critical.

\section{Evidence gaps and research recommendations}

Seven of our 14 propositions were not addressed by our IMMS (P8-14) and thus are the basis of the research recommendations. In part, it is important to acknowledge the issues are extremely difficult to address. However, equally we are aware of practice and to a lesser extent research in progress with many of these issues.

Propositions 7-10 deal with how professionals approach the challenging issue of getting an accurate picture of a man's relationship and experience of DVA. Being aware of any childhood or previous abuse history and the initial contact of male victims with services.

Whilst there is a lack of formal research internationally, services have been developed in the USA, Canada, some Scandinavian countries and the Antipodes. Respect, London UK (http://respect.uk.net/) have developed a toolkit and national standards for working with male victims of DVA $[29,30]$. This toolkit covers supporting men of all sexualities as well as guidance on 'identifying who is doing what to whom and with what effect' and includes a checklist. This toolkit is based on the primary-level evaluation and participant satisfaction studies of the Respect telephone line [14, 15].

Male victims of DVA are disturbed (and avoid services) because of their perception that they can be treated as perpetrators, yet we know from both the 
- The type of professional care setting does not seem important.

- Initial contact and referral should involve an individual approach \& continuity of care.

- Confidentiality and privacy is paramount in initial contact and ongoing help.

- Professionals should consider importance of timing \& context of questioning.

- Female professional help is acceptable, if not preferable.

- Care professionals need to be aware of, \& avoid 'heterosexism'

- It is essential that a professional is knowledgeable about DVA as well as to what services are available so that signposting is appropriate,

- Care professionals need to be aware that their approach may require helping the penetrator also.

- Men want family \& peer support even if it is not always helpful.

- Emergency legal, financial and medical help should be part of the frontline service.

- Increased visibility and targeting of DVA services towards men is needed.

- Promotion of public awareness and political engagement of male victims of DVA is needed.

Research Recommendations
We still need to determine the most appropriate approach for:
- Potential blurred boundaries of victim-perpetrator
- Hybrid perpetrator-victim experiences
- Den who are/have been victims of CSA
We still need to produce better guidance for:
- The response of police \& the criminal justice system
We still need to determine the most appropriate service for men in terms of
- Access
- Linkage

Fig. 2 Recommendations for policy \& practice and future research

female and male victim data that their perpetrators sometimes present as victims at various points $[3,31]$. Whilst it is important to determine how to address the needs of these perpetrators who sometimes present as victims, these approaches are likely to be rejected by them. True male victims of DVA are equally likely to find these approaches offensive. The DRIVE project currently in progress aims to impact the lives of victims, children and perpetrators by offering a multi-agency intervention and ensuring that the criminal justice system provides a robust response and is likely a potential future source of evidence for the evidence gaps identified by this analysis [32].

Propositions 11-14 ask about service provision for male victims of DVA from all backgrounds whether it is possible to have a single service/point of access, whether these services are linked, and proposition 12 specifically tackles substance/alcohol abuse and mental health support.
In the UK, helplines set up for male victims of DVA are likely to cover wide geographical areas but refer to local services. Blanket local provision would be difficult to justify financially as it is known that relatively small numbers of men are known to access these services [33].

In terms of the high prevalence of alcohol and drug problems in DVA situations, work in the UK focuses on female victims and ongoing work seeks to develop an integrated substance abuse/DVA approach to tackling these challenging issues [34, 35].

Linkage and communication between DVA and related services are difficult as the needs of male victims are diverse, and different services have different approaches. However, as our research shows, and the activities of DVA organisations are evolving, awareness surrounding intersectionality and the multiple barriers to help seeking and disclosure by male victims of DVA is increasing. This in turn can contribute to not only to a more 
nuanced understanding of the experiences of male victims and the obstacles to support but can also lead to a more joined up approach.

The findings of this $I M M S$ fed into the development of the IRIS + integrated general practice-based training and advocacy support intervention program [33]. IRIS + is designed to engage general practices in addressing the needs of women and men experiencing or perpetrating DVA and their children, offering affected patients a direct referral pathway to specialist services [36]. IRIS+ includes elements of training on and specific support for male victims. The feasibility, acceptability and value for money of IRIS+ is currently being tested and the findings of this study will be an important addition to the evidence base of joint primary health care and specialist DVA sector response to male victims.

\section{Strengths and limitations}

This IMMS is based on data obtained from a robust systematic review and has been conducted by an experienced team both in terms of the evidence synthesis methodology and the topic area of DVA. This synthesis is also a component part of the REPROVIDE programme and gains from the expertise of that group [12]. The IMMS approach is becoming established within the evidence synthesis community as a useful tool for understanding complex situations as well as identifying any gaps in the evidence.

The limitation of such an approach are that proposition development is a subjective process reliant on the expertise and objectivity of the proposers. This can be counteracted at least in part by transparency of process and involving a wide variety of stakeholders, as well as consulting with a PPI group. Ideally, we would have consulted the male victim PPI group early in the process during the development of the propositions as opposed asking for their confirmation and comments on them. We were however restricted by the timings and availability of these meetings. In future analysis, we would endeavour to involve all parties in the initial development of the propositions.

Production of an IMMS, is relatively lengthy, requiring conduct of the systematic review and initial synthesis of at least part of the data before moving on to the more complex mixed methods analysis. Careful thought is needed to ensure that a mixed methods synthesis is justified within a project. Our synthesis was part of a large programme of work and we feel justified that its output has not only fed into intervention development but has also high-lighted important evidence gaps in the area of male victims of DVA that need to be addressed in future research. We are aware because of the length of this process there is new evidence which could be assimilated into this IMMS. Three multi-country studies by the same research team have been published in 2020 [37-39].. One of these new studies reenforces the findings of our IMMS on help seeking by male victims and service provision [37]. The second study specifically examines male victims experiences of the criminal justice system and this would add new material to our IMMS [38]. The final study focuses on male victims experiences of female perpetrated violence [39]. In an ideal world we would update this IMMS but we are confident that the evidence summary and conclusions still stands in 2020 .

\section{Conclusions}

Mixed methods synthesis of systematically reviewed evidence is an appropriate and useful research tool to further knowledge. Application of this approach to helpseeking by and service provision to male victims of DVA has informed recommendations for policy and practice as well as highlighting gaps in the research agenda.

\section{Supplementary Information}

The online version contains supplementary material available at https://doi. org/10.1186/s12913-020-05931-x.

Additional file 1 Appendix 1. Themes and subthemes from qualitative synthesis.

\section{Acknowledgements}

The authors would like to thank the Reprovide Patient and Public Involvement group for male victims of domestic violence and abuse for their contribution to this paper.

\section{Authors' contributions}

A. H. led on the synthesis of data. She co-wrote the final paper with all the other authors. L. P. was involved in the discussion of the data and synthesis and contributed to the final content of the paper. E. W. was involved in the discussion of the data, the synthesis and contributed significantly to the final content of the paper. A. M. was involved the discussion of the data and advised on and was involved in the synthesis. She commented on the final content of the paper. E. S. was involved in the discussion of the data and the synthesis and contributed to the final content of the paper. G. F. was involved in discussion of the data in the synthesis and contributed to the final content of the paper. The authors read and approved the final manuscript.

\section{Funding}

This paper presents research funded by the National Institute for Health Research (NIHR) as part of their Programme Development Grant for Applied Research (PGFAR) scheme (RP-PG-0614-20012). The views expressed are those of the authors and not necessarily those of the NHS, the NIHR or the Department of Health.

\section{Availability of data and materials}

Full data extraction and synthesis data are available from the authors although the source data is already in the public domain.

Ethics approval and consent to participate Not applicable to this paper which is secondary analysis of systematic review evidence.

Consent for publication

Not applicable.

Competing interests

There are no competing interests to declare. 


\section{Author details}

'Centre for Academic Primary Care, Population Health Sciences, Bristol Medical School, University of Bristol, Canynge Hall, 39 Whatley Road, Bristol BS8 2PS, England. ${ }^{2}$ The Centre for Gender and Violence Research, School for Policy Studies, Social Science Complex, 8 Priory Road, Bristol BS8 1TZ, England.

Received: 23 April 2020 Accepted: 16 November 2020

Published online: 26 November 2020

\section{References}

1. Gov.uk. 2016. Guidance: domestic violence and abuse. Retrieved from https://www.gov.uk/government/news/new-definition-of-domestic-violence.

2. Harvey S, James-Hanman D. 2015. Developing quality standards for services working with men who have experienced domestic abuse: evidence review: what we know about how men's service provision needs differ. Retrieved from personal communication with http://respect.uk.net/.

3. Hester M, Williamson E, Regan L, Coulter M, Chantler K, Gangoli G. Davenport, R., et al. 2012. Exploring the service and support needs of male, lesbian, gay, bisexual and transgendered and black and other minority ethnic victims of domestic and sexual violence. Retrieved from http://www. bristol.ac.uk/media.

4. Huntley AL, Potter L, Williamson E, Malpass A, Szilassy E, Feder G. Helpseeking by male victims of domestic violence and abuse (DVA): a systematic review and qualitative evidence synthesis. BMJ Open. 2019;9(6):e021960.

5. Higgins JPT, Green S. 2011. Cochrane Handbook for Systematic Reviews of Interventions Version 5.1.0 The Cochrane Collaboration. Retrieved from http://handbook.cochrane.org.

6. Huntley A, Szilassy E, Potter L, Malpass A, Williamson E, Feder G. A mixed method systematic review of interventions in all settings for male victims of Domestic Violence and Abuse (DVA). PROSPERO 2016 CRD42016039999 Available from: https://www.crd.york.ac.uk/prospero/display_record.php?|D= CRD42016039999.

7. Dixon-Woods M, Agarwal S, Jones D, Young B, Sutton A. Synthesising qualitative and quantitative evidence: a review of possible methods. J Health Serv Res Policy. 2005;10(1):45-53.

8. Heyaert M, Hannes K, Onghena P. Using mixed methods research synthesis for literature reviews. Thousand Oaks: Sage; 2016. https://doi.org/10.4135/ 9781506333243.

9. Glenton C, Colvin CJ, Carlsen B, Swartz A, Lewin S, Noyes J, Rashidian A. Barriers and facilitators to the implementation of lay health worker programmes to improve access to maternal and child health: qualitative evidence synthesis. Cochrane Database Syst Rev. 2013;10:CD010414.

10. Puts MTE, Tapscott B, Fitch M, Howell D, Monette J, Wan Chow-Wah D, Krzyzanowska $M$, et al. A systematic review of factors influencing older adult's decision to accept or decline cancer treatment. Cancer Treat Rev. 2015;41(2):197-215.

11. Huntley AL, King AJ, Moore TH, Paterson C, Persad R, Sharp D, Evans M. Methodological exemplar of integrating quantitative and qualitative evidence - supportive care for men with prostate cancer: what are the most important components? J Adv Nurs. 2017;73(1):5-20.

12. REPROVIDE programme (Reaching Everyone Programme of Research On Violence programme In diverse Domestic Environments). Retrieved from http://www.bristol.ac.uk/primaryhealthcare/researchthemes/reprovide/.

13. Robinson A, Rowland J. 2006. The Dyn Project: Supporting Men Experiencing Domestic Abuse. Final Evaluation Report. Retrieved from https://www.researchgate.net/publication/241060697_The_Dyn_Project_ Supporting_Men_Experiencing_Domestic_Abuse.

14. Debbonaire, T. 2008. "I just wanted to talk to someone who would understand" A report of an evaluation of the Men's Advice Line. Retrieved from personal communication with the author via http://respect.uk.net/.

15. Debbonaire, T. 2010. Men's Advice Line client satisfaction survey 2009-10 report. Retrieved from personal communication with the author via http:// respect.uk.net/.

16. Bacchus LJ, Buller AM, Ferrari G, Brzank P, Feder G. "It's always good to ask": a mixed methods study on the perceived role of sexual health practitioners asking gay and bisexual men about experiences of domestic violence and abuse. Trauma Violence Abuse. 2016;12(2):1-23.

17. Donovan C, Hester M, Holmes J, McCarry, M. 2006. Comparing Domestic Abuse in Same Sex and Heterosexual Relationships. Retrieved from http://
www.equation.org.uk/wp-content/uploads/2012/12/Comparing-DomesticAbuse-in-Same-Sex-and-Heterosexual-relationships.pdf.

18. Frierson DT. The Fear of Being Judged: African American Gay Men and Intimate Partner Violence: A Qualitative Study. PhD thesis. Washington DC: Howard University; 2014. p. UMI 3635338.

19. Hines DA, Douglas EM. A closer look at men who sustain intimate terrorism by women. Partn Abus. 2010;1:286-313.

20. Hogan K. 2016. Men's experiences of female-perpetrated intimate partner violence: a qualitative exploration. D Couns Psych. University of the West of England. Retrieved from http://eprints.uwe.ac.uk/28618.

21. Machado A, Hines D, Matos M. Help-seeking and needs of male victims of intimate partner violence in Portugal. Psychol Men Masculinity. 2016;17:255-64

22. McCarrick J, Davis-McCabe C, Hirst-Winthrop S. Men's experiences of the criminal justice system following female perpetrated intimate partner violence. J Fam Viol. 2016;31:203-13.

23. Morgan KJ, Williamson E, Hester M, Jones S, Feder G. Asking men about domestic violence and abuse in a family medicine context: help-seeking and views on the general practitioner role. Aggress Violent Behav. 2014;19:637-42.

24. Morgan W, Wells M. Its deemed unmanly: men's experiences of intimate personal violence (IPV). J Forensic Psychiatr Psychol. 2016;27(3):404-18.

25. Simmons J, Brüggeman AJ, Swahnberg K. Disclosing victimization to health care professionals in Sweden: a constructivist grounded theory study of experiences among men exposed to interpersonal violence. BMJ Open. 2016:6:e010847.

26. Tsui $V$, Leung $P$, Cheung M. Help-seeking among male victims of partner abuse: Men's hard times. J Community Psychol. 2010;38:769-80.

27. Valentine SE, Bankoff M, Pantalone DW. Finding meaning after same-sex partner abuse: a content analysis of experiences of men with HIV. Violence Vict. 2013;28:161-77

28. Parliament UK. (2017). Protecting and supporting victims produced by parliament.UK. Retrieved from https://publications.parliament.uk/pa/cm201 719/cmselect/cmhaff/1015/101506.htm.

29. RESPECT toolkit for work with male victims of domestic abuse (2019) Retrieved from http://respect.uk.net/wp-content/uploads/2019/06/RespectToolkit-for-Work-with-Male-Victims-of-Domestic-Abuse-2019.pdf.

30. RESPECT male victims' standard-accreditation for services supporting male victims of domestic abuse. Retrieved from http://respect.uk.net/what-wedo/accreditation/respect-male-victims-standard/.

31. Hester M. The three-planet model - towards an understanding of contradictions in approaches to women and children's safety in contexts of domestic violence. Brit J Social Work. 2011;41:837-53.

32. Hester M, Eisenstadt N, Jones C, Magnus L, Morgan K, Bates L. (2019). Evaluation of Year 2 of the Drive Project- A Pilot to Address High Risk Perpetrators of Domestic Abuse. Retrieved from https://researchinformation.bristol.ac.uk/files/192510838/Drive_Year_2_Report.pdf

33. IRISI interventions. Retrieved from http://www.irisdomesticviolence.org.uk/ iris/.

34. The Stella Project. Retrieved from http://www.gldvp.org.uk/the-stellaproject/.

35. ADVANCE programme. Retrieved from https://www.kcl.ac.uk/ioppn/depts/ addictions/research/drugs/advance.

36. Feder G, Davies RA, Baird K, Dunne D, Eldridge S, Griffiths C, Gregor A, et al. Identification and referral to improve safety (IRIS) of women experiencing domestic violence with a primary care training and support programme: a cluster randomised controlled trial. Lancet. 2011;378(9805):1788-95.

37. Lysova A, Hanson K, Dixon L, Douglas EM, Hines DA, Celi EM. Internal and external barriers to help seeking: voices of men who experienced abuse in the intimate relationships. Int J Offender Ther Comp Criminol. 2020; 306624X20919710. https://doi.org/10.1177/0306624X20919710.

38. Lysova A, Hanson K, Dixon L, Douglas EM, Hines DA, Celi EM. A qualitative study of the male victims' experiences with the criminal justice response to intimate partner abuse in four English-speaking countries. Crim Justice Behav. 2020;47(10):1264-81.

39. Dixon L, Treharne GJ, Celi EM, Hines DA, Lysova AV, Douglas EM. Examining Men's experiences of abuse from a female intimate partner in four Englishspeaking countries. J Interpers Violence. 2020;29:886260520922342.

\section{Publisher's Note}

Springer Nature remains neutral with regard to jurisdictional claims in published maps and institutional affiliations. 